\title{
A Thematic-based Meta Analytic Study Regarding the Effect of Creativity on Academic Success and Learning Retention
}

\author{
Faysal Özdas ${ }^{1}$, Veli Batdi \\ ${ }^{1}$ Mardin Artuklu University, Faculty of Literature, Department of Educational Sciences, Mardin, Turkey \\ ${ }^{2}$ Kilis 7 Aralik University, Muallim Rifat Education Faculty, Kilis, Turkey \\ Correspondence: Veli BATDI, Kilis 7 Aralik University, Muallim Rifat Education Faculty, Kilis, 79000, Turkey.
}

Received: December 2, 2016

Accepted: January 10, 2017 Online Published: February 5, 2017

doi:10.11114/jets.v5i3.2043

URL: http://dx.doi.org/10.11114/jets.v5i3.2043

\begin{abstract}
This thematic-based meta-analytic study aims to examine the effect of creativity on the academic success and learning retention scores of students. In the context of this aim, 18 out of 225 studies regarding creativity that were carried out between 2001 and 2011 have been obtained from certain national and international databases. The studies involving thematic-based meta-analytic reviews are examined under four themes - creative thinking, creative thinking activities, creative thinking techniques and creative writing applications. Certain inclusion criteria are also taken into consideration in the analysis. The statistical programs Comprehensive Meta-Analysis (CMA) and MetaWin are made use in order to analyze the data. The inter-rater reliability of the studies is calculated and found to be high. The Meta-analytic research results indicate that the effect size of creative thinking, creative thinking activities, creative thinking techniques and creative writing applications on academic success are large in terms of levels, while the creative applications in terms of learning retention are again large. This means that creativity has positive and great effects on both academic success and learning retention. The values of Fail-safe Number with regard to considering the effects of creative applications on academic success and learning retention show the high reliability of meta-analysis. It can be suggested that researchers should carry out more studies on creativity as there are not enough studies on creativity, especially regarding retention.
\end{abstract}

Keywords: creativity, academic success, learning retention, thematic-based meta-analysis

\section{Introduction}

Creative thinking skills are among the basic skills that should be included in educational curricula. At the core of these skills are obtaining information, generating knowledge, constructing knowledge, analyzing, achieving synthesis, evaluating, and creative thinking. Creative thinking is a basic skill that must be developed in schools. Nowadays, as information is produced so intensely, the creativity of individuals should be revealed; knowledge should be provided at any place and time when needed. All of these situations can only be of value to those individuals who have acquired creative skills.

The learning environment should be one in which the student can think and behave freely, while offering sufficient structural and pedagogical opportunities to achieve maximum student development (Sakiz, 2016). This environment can enable creative attitudes and behaviors to emerge more easily in that the student is organized in such a way as to be able to recognize the problem, to test it fully and to establish hypotheses (Ozden, 2005). Creativity develops in an environment of love, trust and freedom. Thus, students should be allowed to state their ideas without hesitation or fear. They should never be punished for incorrect thoughts and should be rewarded for creative thoughts and behaviors (Sprinthall \& Sprinthall, 1977, cited in Un Acikgoz, 2009). This is because rewards can encourage creative thoughts and actions and can turn them into habits (Ozden, 2005, p.191). The preparation of such a creative learning environment depends mostly on the role of the teacher. The strategies, methods and techniques used by the teacher in organizing the learning environment and communicating with the learners during the learning process can affect their creativity/creative thinking directly or indirectly.

Creative thinking includes “...the process of allowing students to change, incorporate, reuse, or create new and different products and information within different perspectives, having different viewpoints towards events, and making even major or minor inventions. In addition, developing and enriching detailed ideas, finding unique and private solutions to 
problems, bringing out ideas and solutions; viewing a product or an idea with various perspectives or with a holistic approach" (Ministry of Education, 2005). Creative thinking requires skill. In order to reveal that skill, certain characteristics such as fluency, flexibility and authenticity must be found in the individual (Gartenhaus \& Ruhiser, 2000). For example, the introduction of a new spice to a meal, or the introduction of a different and new interpretation of a known piece of music, can be described as creativity (Brinkman, 2010). Therefore, in order to reveal the creative skills of students, learning environments that are organized in such a way as to be fluent, flexible and unique, and that comprise new and surprising events, can be prepared for them.

While creative thinking concerns mental activities (Akpinar, 2013), creativity is related to both emotional and mental activities, and relates to any kind of effort and endeavor (Ozden, 2005). Dogan (2011) stated that creativity is the skill to reveal, to form, to create and to discover new or original thoughts, or to produce new products. In addition, Sunbul (2011) expressed that creativity is the act of being sensitive towards problems; determining the deficiencies, gaps and difficulties of knowledge; assessing hypotheses, detecting the possibilities and retrying them, and finally making a relationship with the results. Another definition of creativity can be stated as "... a cognitive process in which the environment or the problem is seen as new and original." (Solso, Maclin \& Maclin, 2010). Creativity can be experienced on the part of independent and autonomous individuals. Moreover, there is a need to provide a convenient facility and media for these individuals. Creativity in an individual, therefore, is developed by either external or internal pressure. In terms of internal pressure, the inner world of the individual should achieve creative independence (Inam, 1993). The related process may be supported by exposing the individual to free and unrestricted situations in the learning environment and by making them think differently.

Creativity is a process incorporating originality, adaptation and realization; it is also relates to a person's capacity to produce new original opinions, insights, inventions or productions that are considered by experts as being of scientific, social and technological value. In learning environments in which creativity is recognized, it is not because the teachers carefully organize a creative atmosphere in the process; it is because creative approaches and possibilities support the relationship between teachers, students and the atmosphere of the class (Jones \& Wyse, 2004). Thus, teachers, students and the learning environment need to work together so as to ensure a well-balanced relationship. The current paper aims to pay attention to the subject of creativity, and to determine the impact of creativity on academic success and learning retention.

\subsection{The Purpose of the Research}

In the present research, an attempt has been made to determine the effect of creativity on academic success and retention. In the literature review, certain expressions related to creativity such as "creative thinking", "creative thinking techniques" and "creative performance" are recognized. As these terms are all related to creativity, some of them are selected as the themes for the current research. In addition, while searching the literature, some national studies (Ceran, 2010; Kalkanci, 1991; Kilic, 2009; Ozcelik \& Aydeniz, 2012; Solmaz, 1997) and international research studies (Anwar, Aness, Naseer, Khizar \& Muhammad, 2012; Candrasekaran, 2013; Tierney \& Farmer, 2011) concerning creativity are recorded. However, there seems to be a limited number of articles that examine the effect of creativity on both academic success and learning retention, and include the meta-analytic method that is defined as re-analyzing the results of the studies selected in terms of inclusion criteria (i.e. Byron, Khazanchi \& Nazarian, 2010). As a result of meta-analytic reviews, findings collected from different studies have been combined, and general and comprehensive conclusions have been reached. Within this primary aim, answers to the following questions are sought to address the sub-problems related to the research:

1) What is the effect size of the creative applications [Creative Thinking (CT), Creative Thinking Activities (CTA), Creative Thinking Techniques (CTT) and Creative Writing Applications (CWA)] on academic success?

2) What is the effect size of these same creative applications on learning retention?

\section{Methodology}

The present study makes use of a meta-analysis method in which a quantitative and formal study design is used to systematically assess previous research studies and to arrive at results about the body of research (Haidich, 2010). In the process of arriving at a general conclusion, the results from different studies regarding the same topics, but collected independently of one another, are re-analyzed and combined to specify the effect of the related topic on the level of learning retention on the part of students (Glass, 1976).

\subsection{Literature Review}

A comprehensive literature search of studies carried out between 2001 and 2011 is conducted by using national and international educational databases [Proquest Dissertations and Theses, Google Scholar, the Council of Higher 
Education National Thesis Center, Ebscohost-Eric]. While searching for the subject under consideration, such keywords as creative thinking (CT), creative thinking activities (CTA), creative thinking techniques (CTT), creative writing applications (CWA) both in English and Turkish, are used to conduct the search which relates to how the key learning methods are combined with "creativity" and "academic success". As a result of the process, 18 studies are identified. Of this total, seven are about CT, two about CTA, three about CTT, three about CWA and three about creativity on learning retention; all of which are generated from theses (Master's and $\mathrm{PhD}$ ) and articles.

\subsection{Inclusion Criteria}

In line with the following inclusion criteria for choosing studies, 18 of 230 studies have met the criteria and are included in the analysis. The inclusion criteria are as follows: $i$ ) only studies that used experimental and control groups (pretest-posttest control group model) are included. Here, the basic point of the studies is to compare the academic success of a group of students who have been instructed through one of the various creative learning methods such as CT, CTA, CTT, CWA with their counterparts who have been instructed using traditional teacher-based instruction in terms of promoting creativity. ii) Studies must have reported sample sizes, means and standard deviations, or t-test values, F-test values, or p-values, so that effect sizes can be calculated (Cooper \& Hedges, 1994). iii) Studies are selected which have been conducted in any country, but the report had to be available in English or Turkish. iv) Studies should have been carried out between 2001 and 2011.

\subsection{Coding of Studies}

In order to identify and explain the studies included in the analysis in detail, studies are coded in three phases. In the first phase of coding which is entitled "study identity", the study features are categorized such as with regard to the name of the study, the years of publication, the type of publication (published or unpublished), and the authors' information. On the other hand, some information related to the course type, grade levels, and the duration of implementation (weeks, days, months, and terms) are given in the second phase of coding. Finally, sample sizes, means and standard deviation values used in the meta-analytic calculation are given in the third phase of the coding process and entitled "study data".

\subsection{Independent Variable(s) and Dependent Variable(s)}

As with any experimental and correlational study, meta-analytic reviews include both dependent and independent variables. The independent variables are regarded as study characteristics in the meta-analysis. Study characteristics are related to publication histories (the information concerning publication type, publication year, and author), grade levels, duration of implementation, and study data (value of sample sizes, mean and standard deviation). The dependent variables for this meta-analytic review, on the other hand, are the academic success and the retention scores of students. In order to determine the effect sizes for the dependent variables of academic success and learning retention scores, various experimental settings and tasks are made use of in the studies.

\subsection{Statistical Analysis}

The collected data are analyzed statistically by using Comprehensive Meta-Analysis (CMA) and MetaWin statistical programs. In meta-analytic studies, there is a statistical value which is calculated so as to reveal the efficiency of the pre-determined factor on the independent variable compared to the counter factor on the same variable. This is referred to as the effect size, and is a way of quantifying the size difference between the experimental and the control groups (Coe, 2002). In this study, Hedges' $d$ formula is useful for the effect size estimation, defined as the difference between the experimental and the comparison groups' means, divided by the standard deviation (Cooper \& Hedges, 1994). In addition, so as to determine the total heterogeneity of a sample, a $Q$ statistic which is distributed as a chi-square distribution with k-1 degrees of freedom is used. The k-1 degree of freedom chi-square $(\chi 2)$ heterogeneity test is considered as the most common test approach to determine heterogeneity by Cochran (Higgins, Thompson, Deeks \& Altman, 2003). In order to determine the effect sizes, two models entitled fixed effect models (FEM) and random effects models (REM) are preferred. In terms of FEM, there is a common effect size that underlies all the studies in the analysis, and all studies share a common effect size, while sometimes for REM the effect size varies from study to study (Borenstein, Hedges, Higgins \& Rothstein, 2010). At the end of the analytical process, all the statistical data included in the analysis are formed into a common value which has previously been called "the effect size". Then, the values are interpreted using Cohen's (1992) calculation classification which indicates that there is small level of effect size if ES $\geq$ $0.20 \leq 0.50$; moderate if $\mathrm{ES} \geq 0.50<0.80$ and large if $\mathrm{ES} \geq 0.80$ (Middel \& Van Sonderen, 2002). Furthermore, in order to ensure the level of reliability, the research outcomes are calculated using two encoders who have enough experience of the related studies. In order to validate the inter-rater reliability of the studies which are included in the present research, Miles and Huberman's (1994) formula [agreement / (agreement + disagreement) x 100] is applied, and it is found to be $100 \%$. The result shows that the reliability between the researchers and coder is very high. 


\section{Results}

This section of the study includes the results regarding the effect of creative thinking applications (CTAps) compared to traditional approaches on academic success and learning retention following the thematic-based meta-analytic reviews. As part of this main aim we answer the question Do creative learning environments have an effect on academic success and learning retention? If so, to what is the effect of creativity?. While the studies related to creative applications are included in the analysis, they are categorized into four themes as CT, CTA, CTT and CWA. The analysis of each theme is given separately in Table 1 below. Moreover, the analytical data associated with the studies included in the research in terms of their retention scores are presented in Table 2, together with the distribution of homogeneous values, average effect sizes and confidence intervals. In addition, the values of the Fail-safe number $\left(\mathrm{FS}_{\mathrm{N}}\right)$ calculated through the MetaWin program according to the themes of the included studies, and the applied test-types are presented in Table 3.

3.1 The Results of the Studies Included in the Meta-analysis in Terms of Academic Success Scores Grouped as Thematic-based

The studies included in the research have been thematized into four groups, one of which is $C T$. The results of the general effect sizes regarding academic success of the studies related to the effect of this theme, and included in the meta-analysis, are indicated in Table 1. As the Q statistical homogeneity test value is seen to be significant, and the fact that changes in the effect sizes is greater than that of changes due to sampling error (Lipsey \& Wilson, 2001), REM is accepted for the analysis of these studies.

Table 1. The distribution of homogeneous values, average effect sizes and confidence interval of the studies included in the meta-analysis

\begin{tabular}{cccccccccc}
\hline CTAps & $\begin{array}{c}\text { Model } \\
\text { Type }\end{array}$ & $\mathrm{n}$ & $\mathrm{Z}$ & $\mathrm{p}$ & $\mathrm{Q}$ & $\mathrm{ES}$ & $\mathrm{3}$ & \multicolumn{2}{c}{ 95\% Confidence Interval } \\
& FEM & 7 & 11.282 & 0.000 & 35.032 & 1.175 & 0.104 & 0.971 & 1.360 \\
CT & REM & 7 & 5.121 & 0.27326 & 7.592 & 1.336 & 0.261 & 0.825 & 1.847 \\
& FEM & 2 & 4.811 & 0.017 & 5.668 & 0.955 & 0.199 & 0.566 & 1.345 \\
CTA & REM & 2 & 1.845 & 0.31731 & 1.000 & 0.886 & 0.480 & -0.055 & 1.827 \\
& FEM & 3 & 7.737 & 0.000 & 19.911 & 1.317 & 0.170 & 0.984 & 1.651 \\
CTT & REM & 3 & 2.709 & 0.27706 & 2.573 & 1.501 & 0.554 & 0.415 & 2.587 \\
& FEM & 3 & 6.204 & 0.043 & 6.314 & 1.125 & 0.181 & 0.770 & 1.480 \\
CWA & REM & 3 & 3.521 & 0.34038 & 2.152 & 1.150 & 0.327 & 0.510 & 1.790 \\
\hline
\end{tabular}

$\mathbf{d f}_{\mathbf{C T}}: 6 \quad \mathbf{d f}_{\mathrm{CTA}}: 1 \quad \mathbf{d f}_{\mathrm{CTT}}: 2 \quad \mathbf{d f}_{\mathrm{CWA}}: 2$

As the distribution in Table 1 is seen to be heterogeneous, the efficiency of the instruction involving the use of creative applications and that using traditional approaches are compared by means of REM. As a result of the analysis carried out in this way, the standard error is 0.26 and the upper limit for a confidence interval of $95 \%$ is 1.847 , while the lower limit is 0.825 and the effect size is $E S=1.336$. It can be stated that the value of the effect size is in a wide interval according to Cohen's (1992) classification. Consequently, the implementations based on creative thinking have a positive effect on academic success. Moreover, when the statistical significance is calculated according to the $\mathrm{z}$-test, the value is found to be 5.121 ( $\mathrm{p}=0.27326)$. According to the data from seven studies analyzed through the use of REM, the value of the $Q$ statistical homogenous test is calculated as 7.592. In a 95\% significance level from the $\chi 2$ (chi-square) table, the critical value, with six degrees of freedom, is found to be 12.592 . Therefore, as the $\mathrm{Q}$ statistical value does not exceed the critical value of the $\chi 2$ distribution, the homogeneity belonging to the distribution of effect sizes is accepted in the REM. In other words, it can be inferred that the distribution of the effect sizes has a homogeneous nature in terms of the REM.

The statistical analysis of two studies under the theme of CTA is presented in Table 1. Following the analysis of these studies according to the REM, the average effect size is found to be 0.886 in favor of CTA. The calculated effect size is 
seen to be wide, according to Cohen (1992). The z-test calculation for the statistical significance indicates that the $\mathrm{z}$ value is 1.845 , while the value of $\mathrm{p}$ is 0.31731 . This means that there is no statistical significance. On the other hand, the scores of the studies included in the meta-analysis in terms of CTT are calculated according to the REM. Following the analysis associated with the related model, the standard error is calculated as 0.554 , and the upper limit for the $95 \%$ confidence interval is 21587 , while the lower limit is 0.415 and the average effect size 1.501 . This value is understood to be in favor of CTT. According to Cohen (1992), the value can be expressed to be in wide range which can be also interpreted as taking the view that the students' scores with the use of CTT is greater than with the use of traditional approaches.

The scores of the three studies regarding CWA are analyzed following the inclusion of these three studies in the meta-analysis. With a $95 \%$ significance level from the $\chi^{2}$ table, the distribution of $\chi^{2}$ with two degrees of freedom is found to be 5.991. As it is recorded that a $Q$ statistical value of 6.314 exceeds the critical value $(\chi 2(0.95)=5.991)$, analyses are done according to the REM. Thus, the average effect size is found to be 1.150 and in favor of CWA. Moreover, the calculated $z$-test value is found to be $z=3.521$, while the value of $p$ is 0.34038 . These values reveal that there is no statistical significance in the analysis. In this section we have considered the analytic results of academic success scores regarding CT, CTA, CTT and CWA. However, a limited number of studies relevant to the inclusion criteria have been identified; thus, instead of arriving at a final judgment, it is preferred to consider only the current situation. At this point, Rosenberg, Adams and Gurevitch (2000) state that the value of Hedges's g which is used for calculating the effect size can give good results, with at least 5 comparisons. So, in order to generalize the results of the analyses to the related group, there is a need to involve more studies that have been conducted at national and international levels in terms of CWA.

\subsection{The Results of the Studies Included in the Meta-analysis in Terms of Learning Retention Scores}

Table 2. The distribution of homogeneous values, average effect sizes, confidence interval of studies involving retention scores and included in the meta-analysis

\begin{tabular}{lccccccccc}
\hline \multirow{2}{*}{ Test Type } & $\begin{array}{c}\text { Model } \\
\text { Type }\end{array}$ & $\mathrm{n}$ & $\mathrm{Z}$ & $\mathrm{P}$ & $\mathrm{Q}$ & $\mathrm{df}$ & $\mathrm{ES}$ & \multicolumn{2}{c}{ \% 95 Confidence Interval } \\
\hline \multirow{2}{*}{ Retention } & FEM & 3 & 7.230 & 0.072 & 5.255 & 2 & 1.244 & 0.907 & 1.581 \\
\cline { 2 - 9 } & REM & 3 & 4.365 & 0.000 & 1.826 & 2 & 1.311 & 0.723 & 1.900
\end{tabular}

The retention scores of the studies regarding creative thinking applications (CTAps) are analyzed with the use of the convenient SEM model. The distribution of the homogeneous values, average effect sizes and confidence intervals are presented in Table 2. The effect of CTAps on retention scores according to FEM is calculated and the effect size is found to be as ES=1.244. This value is in wide interval according to Cohen's (1992) classification. Thus, the effect of CTAps is recorded to be positive on retention scores. On the other hand, the Q statistical value is calculated at 5.255, while the critical value is found to be 5.991 at a $95 \%$ significance level from the $\chi^{2}$ table with two degrees of freedom. As can be seen, the Q statistical value (5.255) is less than the critical value (5.991). Consequently, the distribution of the effect sizes is stated to be homogeneous, and is accepted in the FEM. However, it is thought that the analyses may also be made in the REM. As a result of calculations in terms of the REM, at a 95\% confidence interval, the upper limit is 1.900 , the lower limit is 0.723 and the effect size is 1.311 . The effect size value is accepted in the large effect interval according to Cohen (1992), which means that the use of CTAps have a positive effect on retention.

Table 3. The fail-safe numbers of studies included in the meta-analysis according to themes and type of test

\begin{tabular}{cccccc}
\hline (Theme) & $\mathbf{n}$ & $\mathbf{F}_{\mathbf{S N}}$ & Test Type & $\mathbf{n}$ & FS $_{\mathbf{N}}$ \\
\hline CT & 7 & 348.6 & & & \\
CTA & 2 & 13.2 & & & \\
CTT & 3 & 69.7 & Retention & 3 & \\
CWA & 3 & 39.4 & & & \\
\hline
\end{tabular}

In meta-analytic studies, a crucial problem may be that of publication bias in the studies included in the meta-analyses (Rothstein, Sutton \& Borenstein, 2005; Vevea \& Woods, 2005). It is generally preferred to choose published studies for the analysis which is supposed as a threat as the published studies are based on analyses resulting in measures of statistical significance. As there is a probable threat of publication bias, certain strategies have been suggested for eliminating or preventing such bias, one of which is to determine the fail-safe number $\left(\mathrm{FS}_{\mathrm{N}}\right)$ developed by Rosenthal's 
(1978) with the aim of estimating the number of unidentified (not including statistical significance) studies. In this study, the values of $\mathrm{FS}_{\mathrm{N}}$ considering the effects of CT, CTA, CTT and CWA on academic success are found to be 348.6; 13.2; 69.7; 39.4 respectively, through the MetaWin program. On the other hand, the calculated value of $\mathrm{FS}_{\mathrm{N}}$ related to the effect of CTAps on retention scores is found to be 54.2. These results mean that when some more studies exceeding the related $\mathrm{FS}_{\mathrm{N}}$ number were included in the analysis, the effect size of CT, CTA, CTT and CWA on academic success and the CTAps on retention would drop to .001. If the numbers of studies that have been included in the analyses are taken into account ( $\mathrm{CT}_{\text {Academic success }}: 7, \mathrm{CTA}_{\text {Academic success }}: 2, \mathrm{CTT}_{\text {Academic success }}: 3$ and $\left.\mathrm{CWA}_{\text {Academic success: }}: 3, \mathrm{CTAps}_{\text {Retention }}: 3\right)$, it can be stated that the $\mathrm{FS}_{\mathrm{N}}$ numbers very high and the results can be accepted as reliable.

\section{Conclusion and Discussion}

In this section of the research, it is intended to discuss the thematic-based meta-analytical quantitative data regarding the effects of CT, CTA, CTT and CWA on academic success and of CTAps on learning retention scores. With this main aim, the results of the creative-based themes above are compared with results of other studies conducted. The results are all correlated with each other. Afterwards, common results acquired from the data are put forward, together with certain suggestions.

One of the purposes of the meta-analytic study has been to examine the efficiency of CT on the academic success of students. When the criterion made use of in the analysis is considered, the effect size of the studies, including students' academic success scores, is found to be 1.175 according to the REM. This value can be considered to be a high one, positive and significant, according to Cohen's classification (1992). Consequently, it can be thought that the efficiency level of CT on academic success is quite high. The result of the study is consistent with both the results of different studies included in the analysis which have demonstrated positive effect sizes (Emir, 2001; Karatas Ozturk, 2007; Aksoy, 2005; Kadayifci, 2008; Ozturk, 2010; Arif Ozerbas, 2011; Koray, Ozdemir, Koksal \& Presley, 2007) and also the results of articles (Derin \& Demirel, 2011); proposals (Koray, Yaman \& Altuncekic, 2004) and dissertations (Vural, 2008; Ayverdi, 2012) which are not included in the meta-analysis. It can be concluded that the results achieved from the above-mentioned studies, and the current study results including the effect of CT on academic success, are quite consistent with each other.

The other aim of the study is to determine the effect of CTA on academic success. Thus the homogeneity test of the studies related to CTA is revealed to be heterogeneous. This means that the data cannot be generalized to the whole population. The calculations are analyzed with respect to the REM instead of the FEM. The results associated with the REM show that the effect size of CTA is found to be 0.886 in favor of CTA. This result can be interpreted as suggesting that the related CTA has a greater effect on academic success scores than do traditional teaching methods. Cohen (1992) also states that this value has a wide interval. In the learning environments in which CTA exists, students are expected to be more successful than those in which traditional approaches are used. The related result obtained from the studies included in the meta-analysis (Akcam, 2007; Ozcan, 2009) is consistent with the results of studies conducted nationally and internationally (Lu, 2002; Karatas \& Ozcan, 2010).

The next research result relates to the scores of studies which are related to CTT. Following the analysis in accordance with the REM, the average effect size is found to be 1.501 in favor of CTT. The related effect size is considered to be at a wide interval according to Cohen (1992) which can be interpreted as indicating that the scores of students with CTT applications is greater than that of those taught traditionally. This result is also supported by the studies having wide, positive, meaningful values and which are included in the analysis (Candar, 2009; Ceran, 2010; Gungor, 2006). It can therefore be concluded from the results of the studies that the efficacy level of CTT is quite high.

The studies concerning the CWA and including the meta-analytic criteria (Ozturk, 2007; Tonyali, 2010; Temizkan, 2011) are analyzed with respect to the REM. The effect size is calculated as 1.150 in favor of using CWA in the learning environment. The wide, positive and meaningful value of this result means that the effect level of CWA is high in terms of increasing the students' academic success scores. Similar results can be seen in certain national and international Master's and PhD theses (Acikgoz Karakas, 2011; Aktas, 2009; Beydemir, 2010; Pardlow, 2003) which are not included in the analysis. In other words, it can be concluded that the related applications have a greater effect on the academic success scores of students than traditional approaches. So, it can be recorded that the above-mentioned result of the meta-analysis, including the effect of it on academic success, is quite consistent with the related literature. On the other hand, a study conducted by Temizkan and Yalcinkaya (2013) with the purpose of examining the CWA performances of Turkish teachers who teach at $6^{\text {th }}, 7^{\text {th }}$ and $8^{\text {th }}$ grades at secondary school, different results have been obtained. Turkish teachers state that they generally behaved in the same way as the items written in the scale including the planning aspect of story-based CWA in the scale; while different from the ones including the beginning and ending the plot of CWA. In addition, with regard to the aspect of "heroes", they applied some of the items as medium level while the others were lower. On account of the items considered under the aspects of "place", "time" and "others", they 
stated that they applied them at the medium level. It can therefore be concluded that the story-based CWA was not applied sufficiently and at a satisfactory level by Turkish teachers. With the related result, it can be claimed that the role of teachers in applying CWA is of outstanding importance with regard to students' academic success. A PhD dissertation conducted by Ozturk (2007) includes certain remarkable results, one of which reveals that secondary school education is definitely inefficient in terms of developing students' writing skills, and it is underlined that $2 / 3$ of graduating secondary school students cannot write even a simple letter. The related studies stressed that writing activities are not done enthusiastically; thus this reluctance can cause a feeling of boredom. Moreover, the lack of knowledge which is necessary for the development of sub-skills, of interest in the subject matter, and of motivation while writing prevents students from writing attentively. It is of great importance to make students at this level love writing, take pleasure in writing, express their feelings in writing, and to help them develop their creative skills. It is, therefore, a true conclusion to state that the use of creative writing techniques in learning environments can affect students in terms of developing positive attitudes towards writing, enjoying writing and expressing their feelings and thoughts properly. It is suggested that there is a need to use CWA more commonly and in a more conscious way in educational environments.

The effect of creative applications on students' learning retention scores is the last issue examined in this study. The studies including the retention scores of students (Emir, 2001; Ozerbas, 2011; Ozturk, 2010;) are analyzed with respect to FEM. The effect size is calculated as 1.244 which is considered as being in a wide range according to Cohen (1992). With the related value, thus, it can be claimed that creative applications have a positive effect on learning retention. Furthermore, the Q statistical value (5.255) is recorded as being smaller than the critical value (5.991), which means that the distribution of the effect sizes is homogeneous and is accepted in the FEM. On account of the students' retention score results, the experimental group students who have learned in CTAps-based classes have higher retention scores than those of the control group students in teacher-centered classes.

Finally, in this meta-analytic review, the creative applications thematized in four sub-groups as CT, CTA, CTT and CWA have generally a great effect on students' academic success and retention scores. Moreover, more than one database has been searched so as to access both national and international studies concerned with creativity. However, the fact that there are not enough studies on creativity, especially regarding retention scores, emphasizes the need to carry out more studies of creativity.

\section{References}

The references marked with an asterisk (*) are included in the meta-analysis.

Acikgoz, K. O. (2011). The effect of the creative writing techniques to writing skills in English. (Master's thesis). Eskisehir Osmangazi University, Institute of Education Sciences, Eskisehir, Turkey.

*Akcam, M. (2007). Effects of creative activities on students' attitudes and achievements in primary school science courses. (Master's thesis). Balıkesir University, Institute of Science, Balıkesir/Turkey.

Akpinar, B. (2013). Curriculum development in education. Data Publication: Ankara.

*Aksoy, G. (2005). The Effect of the scientific method process, which is based on creative thinking, on the learning outcomes in science instruction. (Master's thesis). Zonguldak Karaelmas University, Institute of Social Sciences, Zonguldak/Turkey.

Aktas, M. (2009). The effect of creative writing on achievement and on writing skill in foreign language teaching. (PhD dissertation). Ankara University, Institute of Social Sciences, Ankara/Turkey.

Anwar, M. N., Aness, M., Khizar, A., Naseer, M., \& Muhammad, G. (2012). Relationship of creative thinking with the academic achievements of secondary school students. International Interdisciplinary Journal of Education, 1(3), 44-47.

Ayverdi, L. (2012). Implementation of scientific creative activity on the 8. grade of primary school science and technology lesson: The example of the unit of 'Cell Division and Genetics'. (Master's Thesis). Balıkesir University, Institute of Science, Balikesir, Turkey.

*Beydemir, A. (2010). The effect of creative writing approach on writing attiude, creative writing and writing achivement in Turkish classes at fifth grade in primary. (Master's thesis). Pamukkale University, Institute of Social Sciences, Denizli/Turkey.

Borenstein, M., Hedges, L. V., Higgins, J., \& Rothstein, H. R. (2010). A basic introduction to fixed-effect and random-effects models for meta-analysis. Research Synthesis Methods, 1(2), 97-111. https://doi.org/10.1002/jrsm.12

Brinkman, W. B. (2010). Attention-deficit/hyperactivity disorder outcomes for children treated in community-based pediatric settings. Arch. Pediatr. Adolesc. Med., 164(2), 160-165. 
Byron, K., Khazanchi, S., \& Nazairan, D. (2010). The relationship between stressors and creativity: a meta-analysis examining competing theoretical models. Journal of Applied Psychology, 95(1), 201-212. https://doi.org/10.1037/a0017868

*Candar, H. (2009). The effects of creative teaching techniques on students' academic achievement, attitude and motivation in science education. (Master's thesis). Marmara University, Institute of Educational Sciences, Istanbul/Turkey.

Candrasekaran, S. (2013). Creativity and academic achievement of higher secondary school students in Tamilnadu. International Journal of Humanities and Social Science Invention, 3(8), 32-36.

*Ceran, S. A. (2010). Effect of science activities created with techniques of creative thinking to student's achievement and attitude. (Master's thesis). Selcuk University, Institute of Educational Sciences, Konya/Turkey.

Coe, R. (2002). It's the effect size, stupid: What effect size is and why it is important. Paper presented at the Annual Conference of the British Educational Research Association, University of Exeter, England, 12-14 September 2002.

Cooper, H., \& Hedges, L. V. (Eds.). (1994). Handbook of research synthesis. New York: Russell Sage.

Derin, N. \& Demirel, E. T. (2011). The effect of organizational creativity on formation of self-organization. Journal of Organizaiton and Management Sciences, 3(2), 255-264.

Dogan N. (2011), Creative thinking and creativity. New trends in education (Ed.Ozcan Demirel), Ankara: Pegem Akademi Publication.

*Emir, S. (2001). The Effects of creative thinking on achievement and retention in social science teaching. (PhD dissertation). Hacettepe University, Institute of Social Sciences, Ankara/Turkey.

Gartenhaus, A., \& Ruhiser, M. (2000). Creative thinking and museums (Trans. Ruhiser Mergenci, Bekir Onur) Ankara: Kid Culture and Research and Application Center. Available from: eBook Collection (EBSCOhost), Ipswich, MA. Accessed Nisan 22, 2015.

Glass, G. V. (1976). Primary, secondary, and meta-analysis of research. Educational Researcher, 5(10), 3-8. https://doi.org/10.3102/0013189X005010003

*Gungor, G. (2006). The effect of using creative thinking methods to student's success in teaching geography. (Master's thesis). Gazi University, Institute of Educational Sciences, Ankara/Turkey.

Haidich, A. B. (2010). Meta-analysis in medical research. Hippokratia, 14(1), 29-37.

Higgins J. P., Thompson, S. G., Deeks, J. J. \& Altman, D.G. (2003). Measuring inconsistency in meta-analyses. British Medical Journal, 2, 557-560. https://doi.org/10.1136/bmj.327.7414.557

Inam, A. (1993). Creativity (Basic terms and theories). Association of Turkish Education, XVII. Educational Meeting, 25-26 October, Safak Publication, Ankara/Turkey.

Jones, R., \& Wyse, D. (2004). Creativity in the primary curriculum. Great Britain: David Fulton Publishers.

*Kadayifci, H. (2008). The effect of an instructional model based on creative thinking on students' conceptual understanding of separation of matter subject and their scientific creativity. ( $\mathrm{PhD}$ dissertation). Gazi University, Institute of Educational Sciences, Ankara, Turkey.

Kalkanci, A. (1991). Using dramatization method in pre-school education. (Master's thesis). Ankara University, Institute of Social Sciences, Ankara, Turkey.

*Karatas, O. S. (2007). The effect of the learning approach based on creative thinking upon the creative thinking and problem solving skills of students. (Master's thesis). Eskisehir Osmangazi University, Institute of Science, Eskisehir, Turkey.

Karatas, S., \& Ozcan, S. (2010). The effects of creative thinking activities on learners' creative thinking and project development skills. Ahi Evran University Journal of Education Faculty, 11(1), 225-243.

Kilic, S. (2009). The effect of creative drama on speaking English and student's attitudes towards speaking English. (Master's thesis). Abant Izzet Baysal University, Institute of Social Sciences, Bolu, Turkey.

*Koray, O., Koksal, M. S., Ozdemir, M., \& Irfan, P. A. (2007). The effect of creative and critical thinking based laboratory applications on academic achievement and science process skills. Elementary Online, 6(3), 377-389.

Koray, O., Yaman, S., \& Altuncekic, A. (2004). The influence creative and critical thinking based on laboratory method on problem solving skills, academic achievement and laboratory attitude level of presevice science teachers. XIII. National Congress of Educational Sciences, 6-9 July, Inonu University, Education Faculty, Malatya, Turkey.

Lu, C. L. (2002). The effects of creating activities on the learning of selected musical concepts and students' learning attitudes. (PhD dissertation).University of Illinois at Urbana-Champaign. 
Ministry of Education (2005). Primary school 1-5. Grades curriculum introduction handbook. Devlet Kitaplar1 Publication: Ankara, Turkey.

Middel, B., \& Van Sonderen, E. (2002). Statistical significant change versus relevant or important change in (quasi) experimental design: some conceptual and methodological problems in estimating magnitude of intervention-related change in health services research. International Journal of Integrated Care, 2(4). https://doi.org/10.5334/ijic.65

*Ozcan, S. (2009). The effects of creative thinking activities on learners' creative thinking and project development skills. (Master's thesis). Gazi University, Institute of Educational Sciences, Ankara, Turkey.

Ozcelik, N., \& Aydeniz, H. (2012). Impact of creative drama method on the academic achievement of university students and their attitude towards speaking French. Ataturk University Journal of Social Sciences Institute, 16(2), 231-248.

Ozden, Y. (2005). Learning and Teaching. Pegem A Publication: Ankara.

*Ozerbas, M. A. (2011). The effect of creative thinking teaching environment on academic achievement and retention of knowledge. GU, Journal of Gazi Education Faculty, 31(3), 675-705.

*Ozturk, D. (2010). The effectiveness of creative thinking skills on 6th grade students' academic achievement in social sciences course. (Master's thesis). Marmara University, Institute of Educational Sciences, Istanbul, Turkey.

*Ozturk, E. (2007). Evaluating the creative writing skills of the 5th grades of primary education. (PhD dissertation). Gazi University, Institute of Educational Sciences, Konya/Turkey.

Pardlow, D. K. (2003). Flight to flatland: a descriptive study of using creative writing pedagogy to improve the teaching of first-year English composition. Saarburcken: VDM Verlag.

Rosenberg, M.S., Adams, D.C. \& Gurevitch, J. (2000). MetaWin statistical software for meta-analysis version 2.0, Massachusetts, MA: Sinauer Associates Inc.

Rothstein, H. R., Sutton, A. J., \& Borenstein, M. (2005). Publication Bias in Meta-Analysis - Prevention, Assessment and Adjustments. UK: John Wiley \& Sons, Ltd. https://doi.org/10.1002/0470870168

Sakı, H. (2016). Impact of an inclusive programme on achievement, attendance and perceptions towards the school climate and social-emotional adaptation among students with disabilities. Educational Psychology, 1(21). https://doi.org/10.1080/01443410.2016.1225001

Solmaz, F. (1997). The effect of creative drama on the six years old children's receive and expressive language development (Master's thesis). Gazi University, Institute of Social Sciences. Ankara, Turkey.

Solso. R. L., Maclin M. K. \& Maclin O. H. (2010). Bilissel Psikoloji. (Cev.Ayse Aycicegi-Dinn), Istanbul Kitabevi.

Sunbul, A. M. (2011). Teaching principles and methods. Konya: Education Academy Publication.

Temizkan, M., \& Yalcınkaya, M. (2013). The state of 6-7-8th grade elementary Turkish-language teachers in applying creative writing activities. Dicle University Journal of Ziya Gokalp Education Faculty, 20, 70-91.

*Temizkan, M. (2011). The effect of creative writing activities on the story writing skill. Educational Sciences, 11(2), 919-940.

Tierney, P., \& Farmer, M. S. (2011). Creative self-efficacy development and creative performance over time. Journal of Applied Psychology, 96(2), 277-293. https://doi.org/10.1037/a0020952

*Tonyal, E. (2010). The effect of creative writing practice on the writing skills of 6th grade primary school students (Master's thesis). Abant Izzet Baysal University Institute of Social Sciences, Bolu/Turkey.

Un, A. K. (2009). Effective learning and teaching. Izmir: Bilis Publication.

Vevea, J. L., \& Woods, C. M. (2005). Publication bias in research synthesis: sensitivity analysis using a priori weight functions. Psychological Methods, 10(4), 428-443. https://doi.org/10.1037/1082-989X.10.4.428

Vural, C. T. (2008). Creative thinking in education of social knowledge: Evaluation of enhancing uses of activities creativity for new elemantary curriculum of fifth class social knowledge education. Cukurova University, Institute of Social Sciences, Adana, Turkey.

\section{Copyrights}

Copyright for this article is retained by the author(s), with first publication rights granted to the journal.

This is an open-access article distributed under the terms and conditions of the Creative Commons Attribution license which permits unrestricted use, distribution, and reproduction in any medium, provided the original work is properly cited. 